\title{
Stanley Brandes, Migración, parentesco y comunidad: tradición y cambio social en un pueblo castellano, Mercedes Gutiérrez (trad.), Madrid, Consejo Superior de Investigaciones Científicas, 2017, 140 pp.
}

La colección De acá y de allá. Fuentes etnográficas del CSIC, que echó a andar en 2009 bajo el impulso de Luis Díaz Viana y que dirige en la actualidad Luisa Abad sigue rescatando tesoros insospechados y al mismo tiempo esenciales de la etnografía y por tanto de la historia cultural de España y del mundo hispánico.

Llega el turno ahora a una monografía cuyo título sonaba, pero de lejos, solo a una secta muy escogida de iniciados. Pese a que tiene rango ya de clásico: un clásico, eso sí, cuyo autor sigue venturosamente vivo y en activo. La edición original de Migration, Kinship, and Community. Tradition and Transition in a Spanish Village vio la luz en Nueva York en 1975, como síntesis de los trabajos de campo que Stanley Brandes llevó a cabo, entre los años 1969 (cuando tenía veintiséis años y era un joven antropólogo recién llegado del Bronx neoyorquino que hablaba español con dificultad) y 1973. El objeto de lo que fue desarrollado como su tesis doctoral (dirigida desde Berkeley por George M. Foster) fue la vida comunitaria de Becedas, un pueblo minúsculo que languidecía sobre un costado de la Sierra de Béjar abulense, atrapado entre una tradición marcada por la decadencia de la economía agropecuaria y un presente y un futuro francamente sombríos, por cuanto el horizonte más fácil y expeditivo que ofrecían a la mano de obra joven y productiva del pueblo era la emigración.

Reconoce Brandes, en el "Prólogo a la edición española", su deuda con

la obra maestra de Julian Pitt-Rivers, People of the Sierra, publicado en 1954 (editado cuarenta años después en castellano bajo el título Un pueblo de la sierra: Grazalema [1989]). Cuando leí este libro por primera vez, era un alumno de licenciatura en la Universidad de Chicago. Y quedé sumamente impresionado por el mismo. De hecho, puedo confesar que fue por People of the Sierra por lo que decidí optar profesionalmente por hacer antropología social y realizar mi tesis doctoral en un lugar de la España rural. People of the Sierra está entre las obras más influyentes de la antropología. Se considera la primera monografía de una comunidad europea llevada a cabo por medios tenidos tradicionalmente como antropológicos, es decir, a base de trabajo de campo y observación participante. Sin duda alguna, People of the Sierra era innovador, hasta tal punto de que E. E. EvansPritchard, el director de tesis de Pitt-Rivers en la Universidad de Oxford, se sintió obligado a defenderlo como estudio antropológico.

En esas mismas páginas preliminares, que concentran y marcan al mismo tiempo una distancia cautelosamente autocrítica con lo que fueron las líneas maestras de una investigación y de un libro por los que ha pasado ya casi medio siglo, desgrana Brandes algunas pistas más que resultan relevantes para entender los presupuestos (al mismo tiempo que algunos de los prejuicios) sobre los que todo el edificio se asentaba:

Ante todo, fueron mayormente los planteamientos teóricos de la antropología social en los Estados Unidos los que me hicieron ignorar cuestiones políticas en general, incluso las 
consecuencias de la Guerra Civil. En los años 1960 y 1970, el estudio del campesinado era una novedad en la antropología social, sobre todo en lo que tenía que ver con sociedades occidentales. La generación de etnógrafos norteamericanos que llegamos primero a España, Irlanda, Italia, Portugal y Grecia teníamos que demostrar que era posible realizar un estudio auténticamente antropológico en un país europeo.

Elegíamos como objetos de estudio pueblos rurales - manejables etnográficamente por su pequeño tamaño-, tecnológicamente primitivos (en términos relativos), tradicionales (supuestamente) con respecto al habla popular, rituales y vida social. Eran pueblos que confirmaban la muy arraigada y antigua visión de comunidades rurales como muestras vivientes de sociedades pre-modernas, dotadas de culturas autóctonas y puras.

Brandes enfatiza, por lo demás, la influencia que en aquellos años ejercía, sobre la nueva antropología que algunos jóvenes de extracción anglosajona intentaban construir en la Europa continental

el marco del estructuralismo social de Radcliffe-Brown, E. E. Evans-Pritchard y otros británicos. Esa línea de descripción y explicación de material predomina en este libro. En la antropología social norteamericana también funcionábamos bajo la gran influencia de psicoanálisis, junto con un afán por los test utilizados mayormente por psicólogos profesionales.

En lo que he publicado aquí sobre dos fenómenos - los procesos migratorios y la soltería - tomo como recurso fundamental el entonces famoso Thematic Apperception Test (TAT). Las historias que contaban los informantes sobre los dibujos presentados en este test forman una base para entender el impacto social tanto de la ola de emigración como del índice alto de solteros y solteras en el pueblo. Si yo tuviera la oportunidad de repetir una investigación sobre Becedas en los mismos años 1969-1973, pero con el ojo crítico que poseo ahora, nunca aplicaría los mismos marcos teóricos de análisis. Sin embargo, el material recopilado y las teorías que forman las bases de análisis siguen dando una perspectiva fiel sobre la antropología anglosajona de la época.

Aquel Migration, Kinship, and Community. Tradition and Transition in a Spanish Village de 1975 que hoy, más de cuarenta años después, llega hasta nosotros como Migración, parentesco y comunidad: tradición y cambio social en un pueblo castellano es hijo paradigmático, en fin, de unos modelos y de unos métodos de trabajo que dieron frutos que no han perdido, ni mucho menos, su valor ni su interés, por más que no se ajusten a los protocolos de actuación y de hermenéutica de ahora. Tampoco hemos de tener demasiada confianza en que los que asumimos nosotros en el día de hoy vayan a mantener su vigencia dentro de cincuenta años. El caso es que la propuesta de Brandes, que fue ejecutada con rigor, objetividad y compromiso, tiene no pocos presupuestos teóricos y metodológicos en común con el clásico de Joseph Buenaventura Aceves que hoy podemos leer, traducido al español y recuperado por esta misma colección De acá y de allá del CSIC, como El Pinar: factores sociales relacionados con el desarrollo rural en un pueblo español. El original de Aceves, quien hizo su investigación en la comarca segoviana de El Pinar, llevaba el título de Social Change in a Spanish Village y vio la luz en 1971.

No fueron los de Aceves y Brandes empeños aislados. En el antes y el después de aquella corriente cabe situar -y citaré solo a antropólogos anglosajones que trabajaron en pueblos de Castilla, y no de otras regiones - a Michael Kenny con A Spanish Tapestry: Town and Country in Castile (1962), Susan Tax Freeman con Dimensions of Change in a Castilian Village (1965), Ruth Behar con The presence of the Past in a Spanish Village. 
Santa María del Monte (1986) y William Kavanagh, con Villagers of the Sierra de Gredos: Transhumant Cattle-raisers in Central Spain (1994). Aquellos jóvenes aventureros no eran del todo conscientes de ello, pero estaban dejando una huella de enorme calado en la historia de la etnografía y de la antropología españolas, colmando carencias por las que nadie hasta entonces se había preocupado, y abriendo caminos que los antropólogos jóvenes del país transitarían después.

Puede que el único intelectual español que estuvo al tanto desde el principio, que supo valorar el significado y que se dejó influir además por aquellas etnografías a contracorriente fuera el inagotablemente curioso, pragmático y (auto)crítico don Julio Caro Baroja, quien en su juventud había mirado mucho hacia la escuela alemana, para girar después, de manera muy decidida, hacia la anglosajona. Don Julio trató y trabajó, instruyó y al mismo tiempo aprendió de antropólogos británicos como Pitt-Rivers y norteamericanos como Foster (el director, ya lo hemos dicho, de la tesis doctoral de Brandes). Después de Caro Baroja, estudiosos que siguieron con atención las andanzas de los jóvenes antropólogos anglosajones por España fueron Carmelo Lisón Tolosana, quien había recibido su formación en la academia británica y, una generación después, Luis Díaz Viana, quien estuvo inmerso en el sistema norteamericano. En la estela de aquellos, Honorio M. Velasco, José Luis Alonso Ponga, Pedro Tomé, Julián López García y unos cuantos más han seguido contribuyendo a la renovación de la comprensión etnográfica de Castilla (conviene aclarar que Lisón trabajó más en Galicia y Aragón que en Castilla, y que definió unos paradigmas que fueron aprovechados por todos los demás, incluidos los castellanistas).

Del resto del establishment académico e institucional español de las décadas de 1950, 1960, 1970, que — descontando a los antropólogos que volvieron del exilio a partir de 1970 más o menos - se sintió más cómodo en las butacas de sus despachos que haciendo trabajo de campo, mejor ni acordarse. Ensimismados como estaban, desde los tiempos de la llamada Generación del 98, si no desde antes, en disertar acerca del alma eterna de Castilla y de los rasgos esenciales del ser de España y de los españoles (y de la hispanidad, por supuesto), ni acusaron recibo siquiera de las presencias y de los métodos de todos aquellos osados jóvenes cuya lengua primera era el inglés. ¿Qué les importaba a ellos que aquellos bárbaros aportasen una fresca desconexión de viejos misticismos patrios o patrioteros, que hiciesen bandera de un empirismo y un objetivismo $-\mathrm{o}$, si se quiere, de un funcionalismo basado en la observación participante - que les hacía pasarse los meses y los años sin salir, o saliendo apenas, de los pueblos en que establecían sus observatorios, y que, para colmo, se mostrasen mucho más interesados por el discurso de la prosaica y decaída sincronía que por la diacronía que conectaba directamente con las glorias del pasado?

El caso es que desde la privilegiada atalaya en la que nos ha colocado a nosotros el paso de las décadas, no puede menos que asombrar la construcción, primero en plena dictadura franquista y después durante la llamada Transición, de una tan densa y pertinaz etnografía, implantada o trasplantada por anglosajones, que enseñó a los propios especialistas españoles a interesarse y a interpretar los cambios en los modos de vida que afectaban sus propios conciudadanos de Castilla. Y a los de España en general, porque la nómina de los nombres y de las monografías sería mucho más profusa si ampliásemos el foco al conjunto de las comunidades de España o de la península Ibérica. En ese caso habrían de subir al podio nombres que van desde el de George M. Foster al que ya hemos citado hasta William A. Christian Jr., a quien seguramente debemos la etnografía más monumental y compleja — centrada sobre todo en la órbita de la religiosidad popular y 
tan atenta a la diacronía como a la sincronía, y a un amplio abanico de regiones, que van desde Cantabria y el País Vasco hasta la vieja Castilla y la Castilla manchega- que haya sido elaborada por un especialista venido de tierras lejanas en nuestro país. Aunque sea danés, y no anglosajón, Gustav Henningsen es otro de los etnógrafos —en su caso etnógrafo y etnohistoriador - que ha contribuido, con obras mayores que todavía están por reconocer, a la descripción e interpretación antropológicas de España, muy singularmente de Galicia. La publicación, en curso, de sus apuntes, fotografías y registros sonoros de la década de 1960 y de los inicios de la siguiente le sitúa entre los antropólogos fundamentales en la España del momento.

Se distanciaba con alguna ironía Brandes, como se ha señalado anteriormente, en su «prólogo a la edición española», de algunos de los principios metodológicos que guiaron su indagación de los años 1969 al 1973 que culminaría con la publicación de su libro en 1975. Reconocía que las normas y cautelas de la escuela de antropología social de los Estados Unidos «me hicieron ignorar cuestiones políticas en general, incluso las consecuencias de la Guerra Civil». Omisión que desde la perspectiva de hoy resulta difícil de justificar, por cuanto guerra, represión, marginación, desarraigo, migración, fueron partes del mismo desalentador escenario sociohistórico, y debieran ser partes, por tanto, del mismo proceso de reflexión. La etnografía de hoy no suele tener ningún escrúpulo en considerar, e incluso en denunciar, el conflicto social, político o bélico como causa del trauma migratorio. En aquellos años la denuncia, el análisis, la mención siquiera, no eran tan fáciles. Hay que meterse en la piel de un joven extranjero de la época, inmerso en un pequeño pueblo de la España rural y franquista, observado con desconfianza por los poderes fácticos y policiales, para entender que aquel discreto apoliticismo debía de ser una estrategia de supervivencia en general, y un requisito sine qua non, en particular, para poder sacar adelante la tarea programada.

Téngase en cuenta que en los mismos años - un poco antes, durante y un poco después de la década de 1960 - en que Pitt-Rivers, Foster o Kenny habían realizado ya y seguían realizando sus expediciones por la España rural, y abriendo el camino a Tax Freeman, Aceves, Brandes, Christian o Henningsen, los pocos españoles que se atrevieron a proponer una etnografía de la denuncia no tuvieron más remedio que ponerse el disfraz de la metáfora literaria. Lo cual no les libró de acosos, denuncias o exilios. Campos de Nijar (1959) de Juan Goytisolo, Caminando por Las Hurdes (1960) de Antonio Ferres y Armando López Salinas, o Tierra de olivos (1964) del mismo Antonio Ferres son libros de viajes que a los antropólogos españoles no les sonarán demasiado, pero que envuelven etnografías de una calidad y de una densidad de información (y también de una crudeza) que se echa en falta en la etnografía que - si descontamos la de Caro Baroja y la de Lisón - se hizo en la sombría y amedrentadora España del momento, de la mano no solo de los españoles, sino también de los anglosajones.

El libro, el método, la escuela o la tradición de Brandes no solo se nos muestran hoy constreñidos por la censura o por la autocensura en cuanto atañe a la raíz política y social que desencadenaron, en alguna medida, los conflictos y procesos que describe. Presentan otras limitaciones que condicionan, también, sus resultados. Puede que para los antropólogos no sea un detalle relevante, pero para quienes nos dedicamos al estudio de la literatura oral y de la historia oral sí lo es, el que Brandes y el resto de los antropólogos anglosajones del momento apenas dejasen margen para la transcripción literal de los discursos de sus informantes, y prefiriesen formular ellos mismos discursos y síntesis descriptivos al tiempo que interpretativos resulta ser un método cuestionable. No porque carezcan de interés las conclusiones que acerca de lo que observaban pudieran sacar los 
antropólogos, sino porque la casi completa suplantación de la voz de la gente por la voz del antropólogo — por más persuasiva e informada que sea- es inevitable que genere discursos orientados y condicionados, además de innecesariamente politizados, por cuanto eleva el logos del observador por encima del logos de sus observados.

Si hacemos abstracción de esos lastres, que tienen más que ver con el dogma metodológico que con la cualificación o el entusiasmo, el libro de Brandes resulta ser de una objetividad, una agudeza y una calidad muy sustantivas. La información que nos regala levanta un fresco insustituible de la vida rural en un pueblo que hoy, al cabo de casi medio siglo de inmersión progresiva en la globalización, se ha convertido en una entidad absolutamente diferente de la que se nos pinta en estas páginas. Particularmente originales son, a mi parecer, las observaciones y las reflexiones, de insólita crudeza muchas veces, que se hacen acerca de las relaciones de amistad y de sus proyecciones socioculturales, las cuales se movían entre los polos de la cooperación comunitaria por un lado y del interés de cada individuo por el otro:

Las amistades en Becedas, aunque cargadas a veces de un tinte emocional, siempre contienen un fuerte elemento de puro interés personal y de intercambio mutuo en los asuntos económicos. Los emigrantes, que con frecuencia actúan de mecenas con los familiares, no lo suelen hacer con los que un día fueron sus amigos porque no recibirían nada a cambio.

Los antiguos amigos, en este caso, son más una obligación que un activo, por lo tanto las relaciones emigrantes-vecinos del pueblo adquieren un carácter al que Yehudi Cohen (1961) llamó «amistad casual», una relación amistosa en la que no existen apenas o incluso ninguna demanda o exigencia real entre ellos.

La traducción, dúctil y elegante, es de Mercedes Gutiérrez. La edición es limpia y hermosa, como todas las que ven la luz en la colección De acá y de allá. Fuentes etnográficas del CSIC.

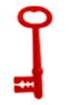

